\title{
An Assistive Examination Processing System Based on Course Objectives Using a Binary Approach Algorithm
}

\author{
Mohammed Alghobiri* and Osman A. Nasr \\ Management Information Systems, King Khalid University, Saudi Arabia
}

\begin{abstract}
Article Type: Article
Article Citation: Mohammed Alghobiri, Osman A. Nasr. An assistive examination processing system based on course objectives using a binary approach algorithm. Indian Journal of Science and Technology. 2020; 13(10), 1135-1147. D0l: 10.17485/ijst/2020/ v013i10/149653
\end{abstract}

Received date: December 14, 2019 Accepted date: February 16, 2020

*Author for correspondence: Mohammed Alghobiri maalghobiri@kku.edu.sa 9 Management Information Systems, King Khalid University, Saudi Arabia

\begin{abstract}
Background/objectives: The process over developing test or question paper for examinations at various levels in higher education is time consuming and requires a lot of work for staff who deal with courses. The objective of the study is to develop a web-based application to help in preparing question papers for examinations. Methods/statistical analysis: This article presents a web-based application that has been developed to help prepare question papers for examinations. Feedback and suggestions from staff at King Khalid University have been used to develop and design the system accordingly. This system will provide a very good tool for fast and accurate development of exam papers. Findings/application: This system allows the administrator to automatically create a repository of question papers for all courses in academic programs at an institute of higher education. Using this system, staff can access previous question papers at any time they need. Moreover, the system is simple to access and can be customized according to staff requirements. The system also accommodates different pattern of questions to be asked, such as true or false questions, multiple choice questions, fill-in-the-gaps questions, and subjective or descriptive questions. Teachers on each semester prepare some set of questions and upload in the question bank database. These questions are developed in the consultation of course teachers, course coordinator, and knowledge area head. Moreover, while framing the questions precisely, the course learning objectives and course learning domain are considered, such as cognitive skills, interpersonal skills, and communication skills. Importantly, the course coordinator takes all necessary measures to make question papers with utmost care, and assures that each question paper covers different level of difficulty. The question paper includes knowledge level, cognitive level, and in some scenarios real-time problem-based question.
\end{abstract}

Keywords: Web-Based, Exam, Course Objectives, Question Paper, Educational Institutions. 


\section{Introduction}

Teaching staff is always looking for more efficient and effective methods to conduct examination for learners at a quick notice with less manpower. Here, we aim to develop a system of online automated examination preparation. As learnt from Refs. [1-2], the effective education systems, assessment, and evaluation processes are no less important than teaching processes. The process of assessment and evaluation is in dispensable for the education and also time consumable and leaves the teaching staff often over-burdened.

Exams are the most common method of assessing students' learning and measuring their performance in an academic course. In academic education, an examination should include the learning skills taught in the course and evaluate the student based on these learning skills. Therefore, when framing exam question papers, the course's learning skills need to be considered and possibly included in question papers. This helps in judging students' knowledge and skills. The results of course evaluation help to determine student competence to move on to the next level in the curriculum hierarchy. But, for staff, framing question papers while considering all these parameters is serious work which requires a lot of effort [3-9].

The proposed system is a Web-based application for preparing examination question papers electronically. This system provides several facilities, such as a question bank for all types of questions, previous question papers, and similar material. When staff prepares question papers, they have to make sure that all course topics are covered. There should be correlation between the topics covered during course delivery and the intended question papers. One significant feature of the proposed system is that it provides staff with all possible questions. Staff has to provide the list of topics covered and the types of questions to be asked, such as true or false questions, multiple-choice questions, fill-inthe-gaps questions, and subjective or descriptive questions. We are sure that this will be a remarkable tool for academic staff, reducing a lot of effort increasing question papers.

\section{Literature Survey}

Academic researchers have proposed many methods of preparing examination question papers and adopted different emerging technologies to develop systems, applications, and tools for this purpose. Several studies have been published on web-based applications for the preparation of examination question papers, of which some are listed below.

In Ref. [10], the issue of examination test papers based on Computer-Based Testing (CBT). This system is gaining popularity among stakeholders in academic education. This system addresses staff and institutional administrative requirements and minimizes their efforts. The study highlighted the features of computer-based test platforms for the Centre of Entrepreneurship Development and Vocational Studies (CEDVS) at the Federal Polytechnic, Ado-Ekiti, Nigeria. The study has identified freely available open source software (FOSS) for this purpose, called MOODLE. This software was used to develop a system for creating examination test papers. The study discussed a specific course offered to students in a polytechnic program for Entrepreneurial Courses, in which this system 
was adopted for conducting tests. Additionally, the study discusses statistics reflecting student attitudes to the system after completing the CBT test.

In Ref. [11], Hameed and Abdullatif discussed Online Examination System (OES), a web-based examination system. This computer-based model provides users with both Internet and intranet networks. The study attempted to produce a system that is going to support staff to conduct exams more effectively. It produces significant results, such as faster access and processing, and more accurate examination results.

In Ref. [12], Garg et al. also focused on OES and described it as a software solution which lets any kind of industry or institution organize, plan, and handle examinations online. This can be done through the Internet, intranet, or Local Area Network. Some difficulties of manual examination systems are the delay occurred in providing results, and difficulty of filtering of documents. The chances of document loss are high, while record enquiry and matching is difficult and time-consuming. System maintenance is also very crucial and requires a lot of time and effort. In the age of technology, examinations using online technology should be feasible and economical options for stakeholders in educational institutions. The OES is dynamic, sufficiently quick and cuts down the huge amount of material required for manual examinations. The web-based examination system does all the work, including question executive, paper design, and online testing [12].

\section{Proposed Methodology}

The methodology we used in this study is a Rapid Application Development (RAD) model. RADs are incremental models where multiple processes occur at the same time as shown in Figure 1 [13].

\subsection{Analysis}

\subsubsection{Objectives Analysis}

This study aims to develop an efficient and effective web application for automatic question settings. The system eliminates time waste which enables the faculty to focus on more

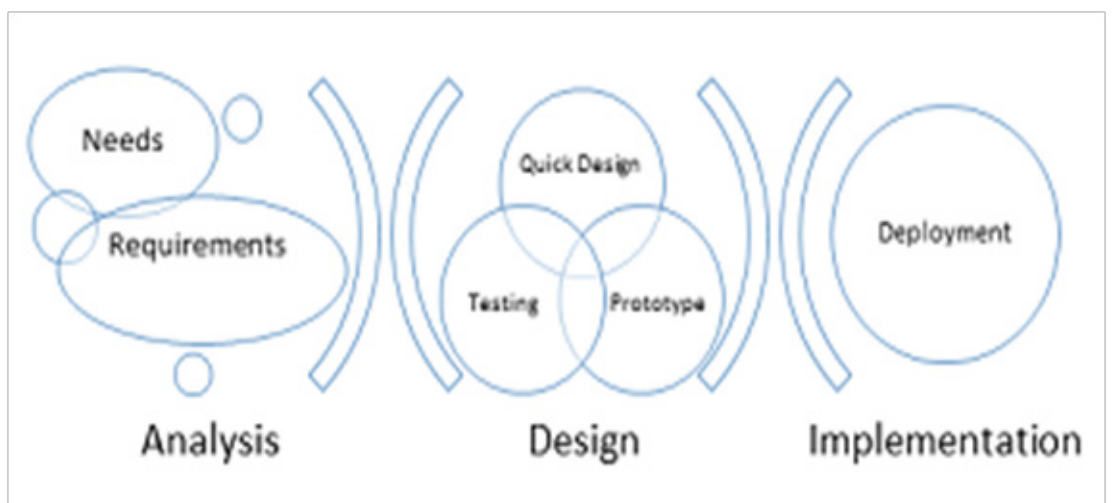

FIGURE 1. Rapid application development model. 
teaching process and on their research work. The desired features of this application are as follows:

- Time saving so that the faculty now work on research and teaching activities.

- A fully automated system gives fast results.

- The ability to create a new set of questionnaire just at the required time gap which enables the whole process safe and secured from misuse.

- Includes an exam repository which records all related data and information in the exclusively designed database. This helps staff in conducting exams using an automated system.

- Questions on the final exam sheet will measure achievement of the course objectives in the course specification.

- Can be used anywhere, anytime, as it is a web-based application.

- All test modules are saved for easy retrieval.

- The university data center takes care of centralized privacy.

- In the updated algorithm, we have included a set of courses and objectives of respective courses. Teachers will select the course for a particular exam with the help of proposed algorithm.

- Has inbuilt piracy proof?; any check for right equation paper to right subject/right syllabus

\subsubsection{Binary Approach Algorithm}

A binary approach is faster than a linear approach except for small records. The algorithm will be implemented through the following steps (Table 1):

1. Define courses $C_{t}=\left\{C_{1}, C_{2}, C_{3}, \ldots, C_{n}\right\}$ Define the course objectives $C_{o b j}=\left\{o b j_{1} . o b j_{2} \cdot o b j_{3} \ldots . . o b j_{n}\right\}$.

2. Define the questions types $Q_{t f}=\left\{q_{t f 1} \cdot q_{t f 2} \cdot q_{t f 3} \ldots . q_{t f n}\right\}$.

TABLE 1. Symbol description

\begin{tabular}{ll}
\hline Symbol & Description \\
\hline$C_{t}$ & Total number of courses \\
$C_{o b j}$ & Course objectives \\
$Q_{t f}$ & True or false question \\
$Q_{t f}$ & Multiple choice question \\
$Q_{e s}$ & Essay question \\
$Q_{s e t}$ & Set of question ( all types of questions) \\
$E X_{t e m p}$ & Temporary variable for exam type \\
$E_{t y p e}[]$ & Exam type \\
$T N Q P$ & Total number of questions \\
$M P Q_{s e t}$ & Mid-point for question category \\
\hline
\end{tabular}




$$
Q_{m c}=\left\{q_{m c 1} \cdot q_{m c 2} \cdot q_{m c 3} \cdots \cdot q_{m c n}\right\} \cdot Q_{e s}=\left\{q_{e s 1} \cdot q_{e s 2} \cdot q_{e s 3} \cdots \cdots q_{e s n}\right\} .
$$

3. Make questions set $Q_{s e t}=\left\{Q_{t f}, Q_{m c}, Q_{e s}\right\} / /$ Questions Database

4. Define exam type $E X_{\text {temp }} \leftarrow E_{\text {type }}\left[M E X_{1}, M E X_{2}, F E X, O E X\right]$.

5. Select Exam type $E X_{\text {temp }}=E_{\text {type }}[]$.

6. Define total number of questions $T N Q P=N O Q_{i f}+N O Q_{m c}+N O Q_{e s} / /$ total number questions of all types

a. Select the questions depend on binary approach :

b. Define the mid-point for question category as: $M P Q_{\text {set }}=\frac{Q_{\text {set }}}{2}$

c. if $M P Q_{\text {set }}=Q_{t f}$ then keep on the $E_{\text {type }} \cup Q_{m c}$ then keep on the $E_{\text {type }} \cup Q_{e s}$ then keep on the $E_{\text {type }}$

d. Check the number of questions on $M P Q_{\text {set }}<T N Q P$ then $M P Q_{\text {set }}+1$ else goto $d$

7. Save the $E_{\text {type }}$

8. End

\subsubsection{Data Collection}

All data were collected through interviews among faculty members (how many? When; in what form?; has it any moderation facility- arrangement from easy to difficult!) at King Khalid University. We asked them why they needed the Exam Processing System, how they set exam questions depending on course objectives, what types of questions they need to frame and retrieve from the system, and what types of exam they need the system to develop as shown in Table 2.

\subsubsection{Analysis Process Diagrams}

The Unified Modelling Language (UML) was used to illustrate the analysis process diagrams. UML is a standard visual modelling language which has also been used for:

- Modelling business and similar processes.

- Analysis, design, and implementation of software-based systems.

TABLE 2. Number and types of peoples involved in the interview

\begin{tabular}{lccl}
\hline Type of user & Total & Years & Time and location \\
\hline Faculty members & 30 & $2018-2019$ & Academic cycle \\
Department authority & 3 & $2018-2019$ & With appointment \\
College authority & 3 & $2018-2019$ & With appointment \\
Academic audit cell & 2 & $2018-2019$ & With appointment \\
\hline
\end{tabular}




\subsubsection{Use Case Diagrams}

A use case diagram represents the behaviours of actors and events involved in a use case. It is a graphical representation of behaviour and dynamics in nature and can be drawn using UML software. Use case diagrams model the functionality of a system using actors and use cases [14]. The use case for this system is shown in Figure 2.

\subsubsection{Activity Diagram}

An activity diagram is another graphical representation of activities, which basically represents the flow of information between the activities. Generally, an activity describes a specific operation of a processing system [15]. The activity diagram for the proposed system is shown in Figure 3.

\subsubsection{Class Diagram}

A class diagram describes the structure of a system. It includes components such as the system's classes, related attributes, operations (or methods), and the relationships among objects [15]. The class diagram for the proposed system is shown in Figure 4.

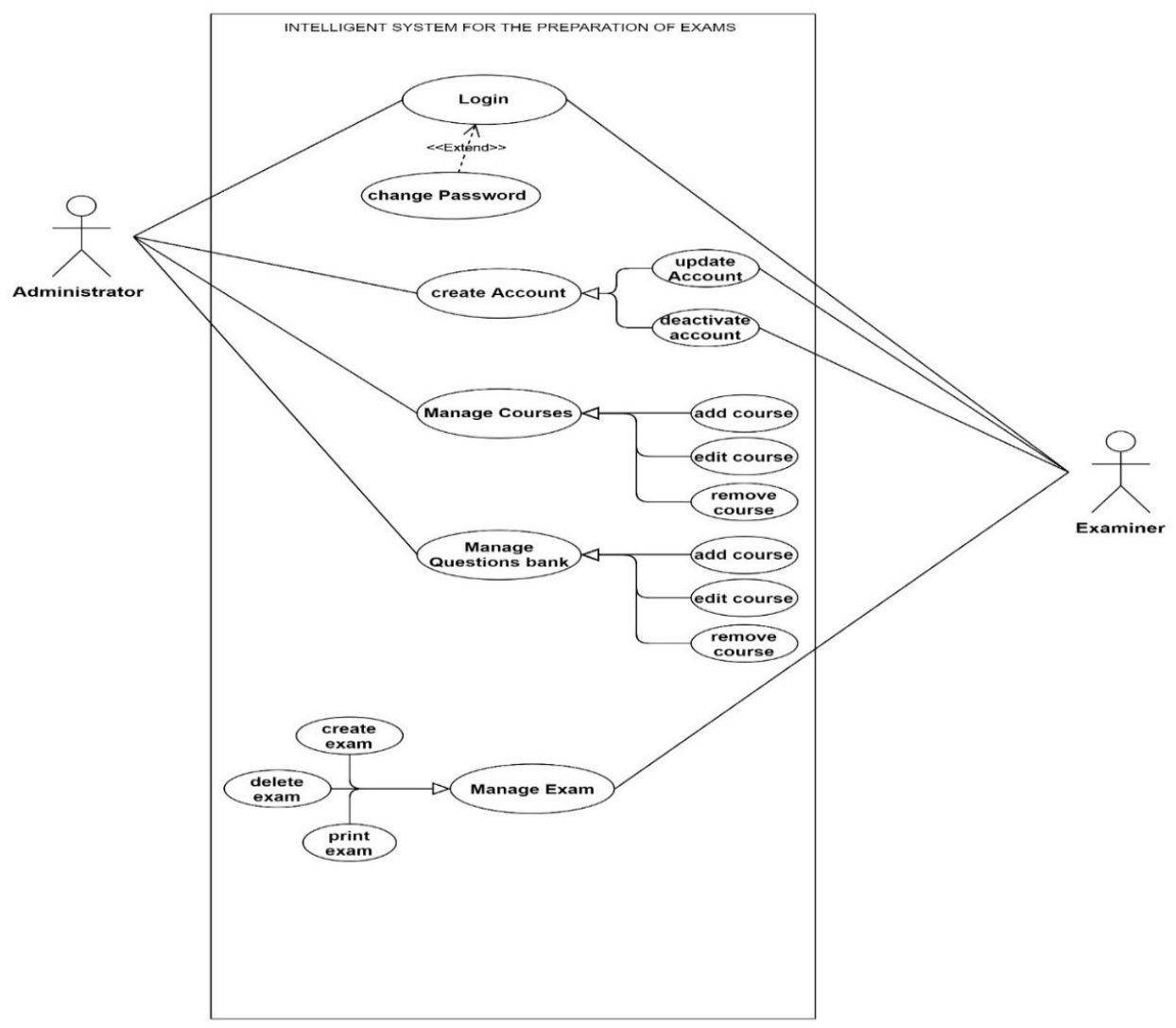

FIGURE 2. Use case diagram for the proposed system. 


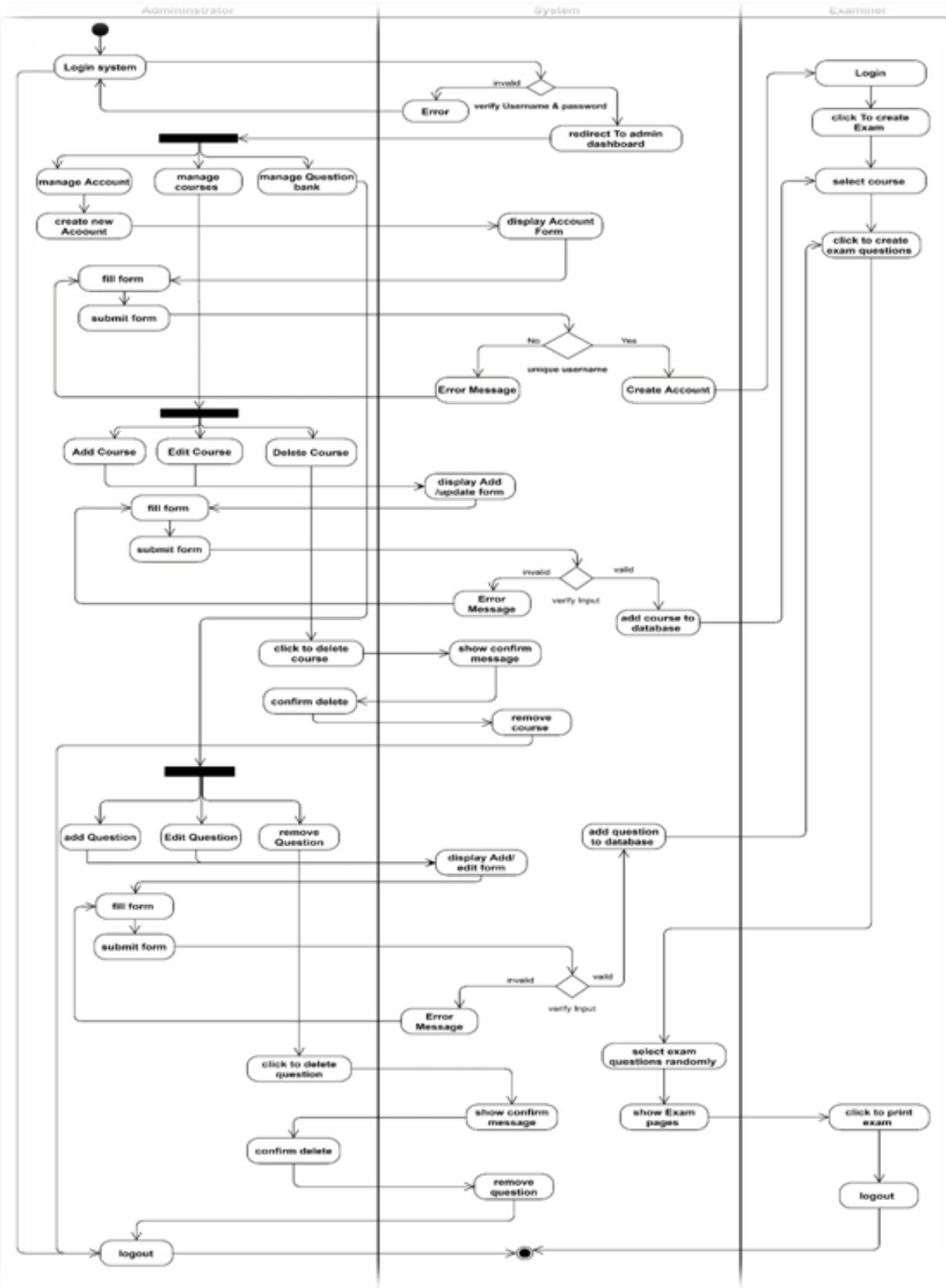

FIGURE 3. Activity diagram.

\subsection{Database Analysis}

\subsubsection{Entity Relationship Diagram}

An entity relationship (ER) diagram describes the relation between the system's entities in a specific domain of knowledge. A basic ER-model is composed of entities and their types 

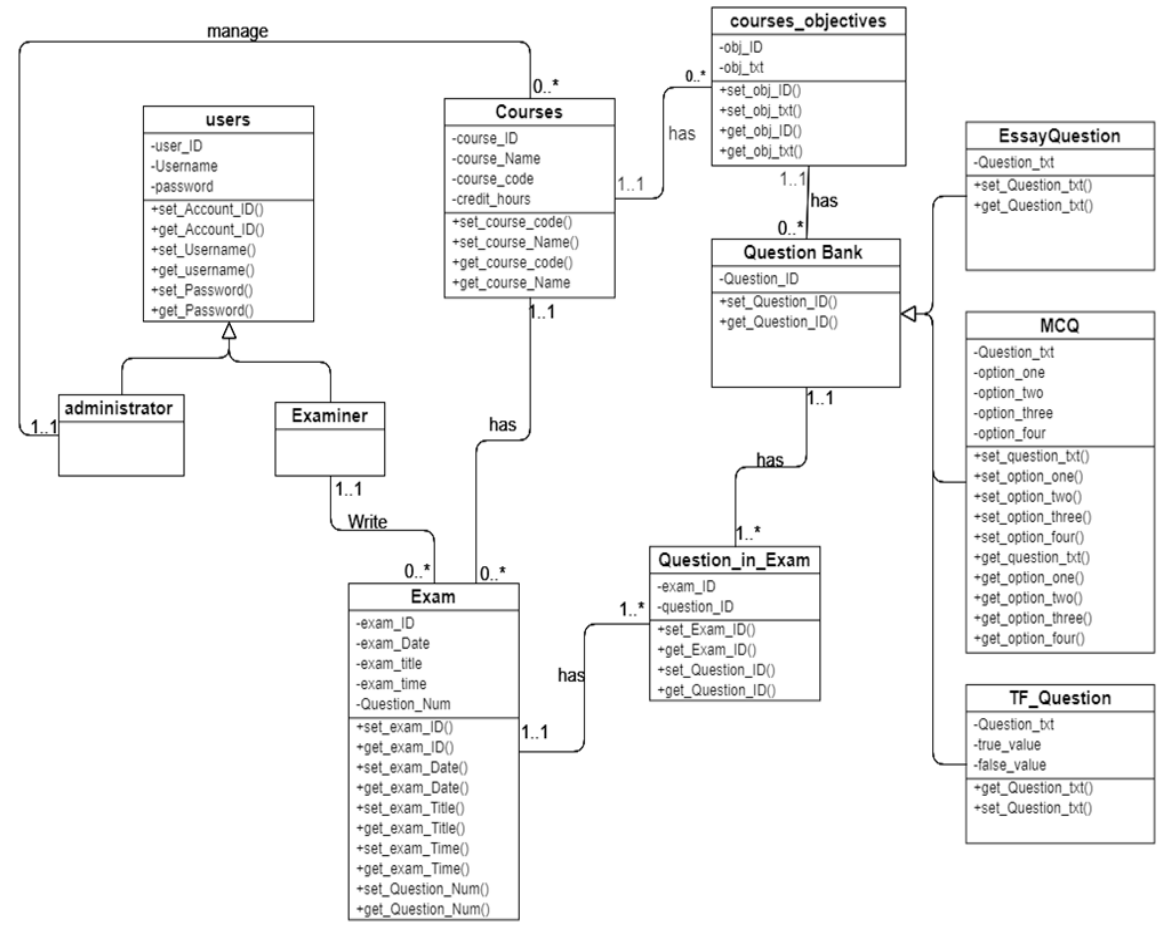

FIGURE 4. Class diagram.

(which classify things of interest). This also specifies the possible relationships between entities of the entire system (instances of those entity types) [16]. The ER diagram for the proposed system is shown in Figure 5.

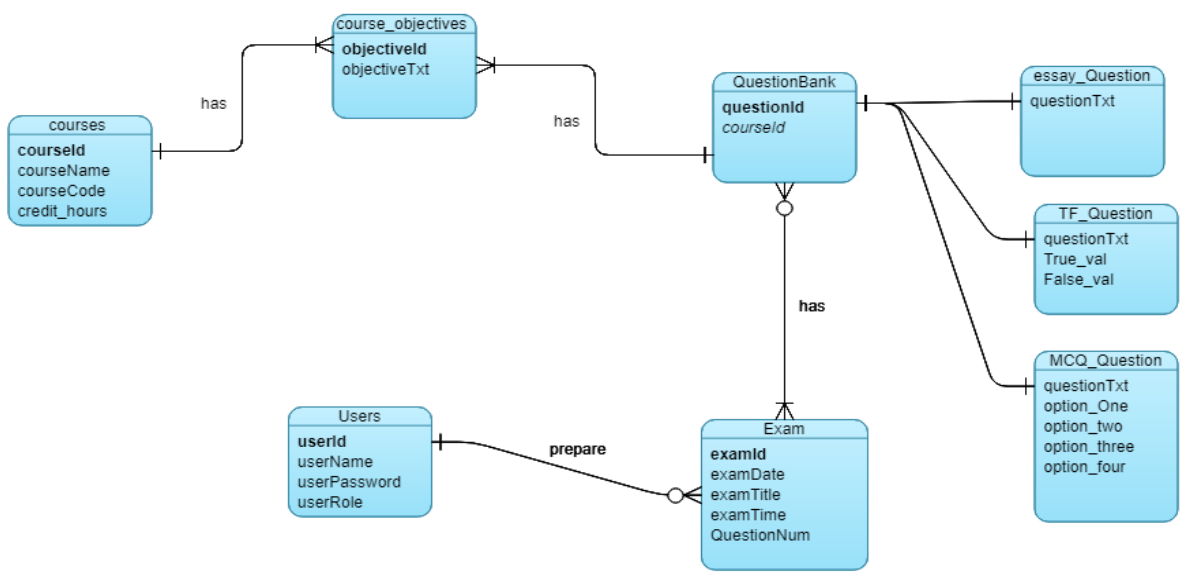

FIGURE 5. Entity relationship model. 


\subsubsection{Relational Model}

The relational model is an approach to data management using a structure and language consistent with first-order predicate logic, where all data are represented in terms of tuples, grouped into relations [1]. A database organized in terms of the relational model is a relational database. The relational model diagram for the proposed system is shown in Figure 6.

\section{Findings and Discussion}

\section{1. "Manage Courses" Page}

The page shown in Figure 7 shows how the administrator of the system can manage course information, including adding a new course, updating course information, and deleting a course from the database.

\section{2. "Manage Course Objectives" Page}

The page shown in Figure 8 allows the administrator to manage course objectives including adding a new course objective, update course objectives, and delete a course objective from the database.

\section{3. "Manage Exams" Page}

The page shown in Figure 9 allows the course coordinator to manage exams, including creating a new exam or deleting an exam from the database.

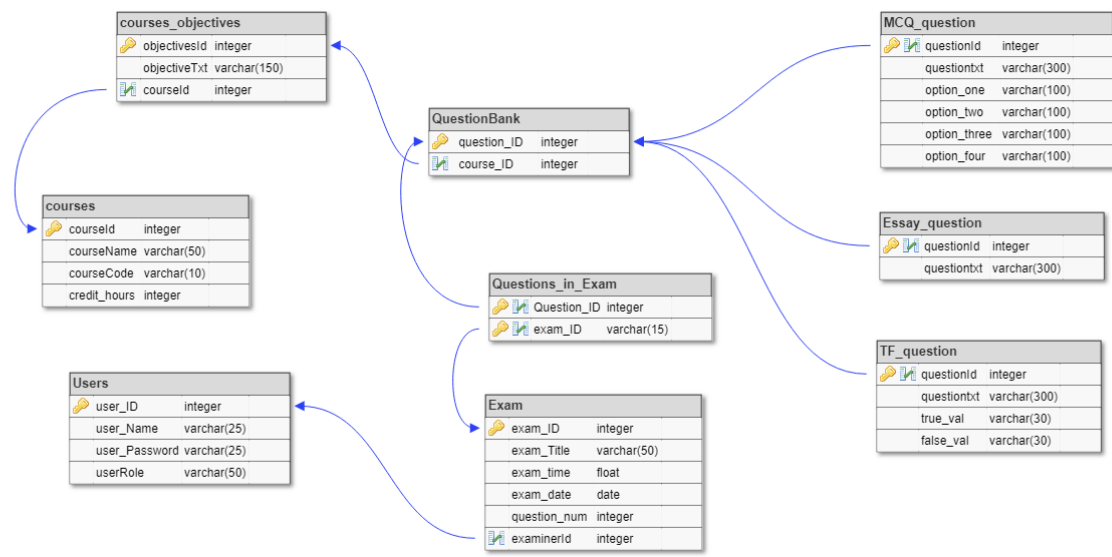

FIGURE 6. Relational model. 

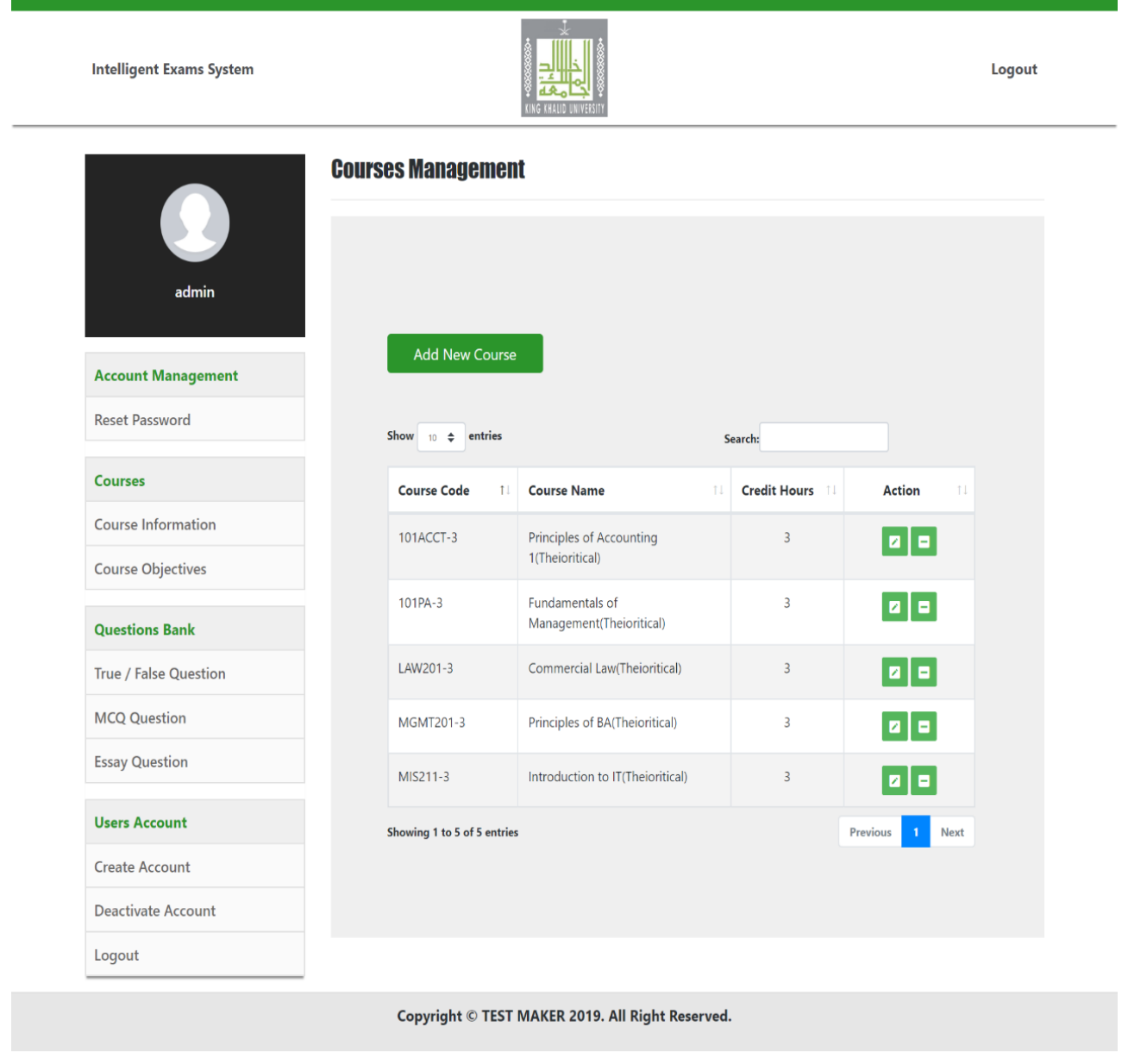

FIGURE 7. Manage courses page.

\section{4. "Create New Exam" Page}

The page shown in Figure 10 allows the course coordinator to create a new exam paper. To do this, the course coordinator will identify basic information related to the exam such as course and course objectives, number of questions, title, date, and time. The system will then create an exam paper based on randomized retrieval of questions.

\section{Results}

The system consists of two modules, the administrator module and the course coordinator module. The admin module allows the system administrator to manage course information, course objectives, exam questions, and user accounts. The course coordinator module allows the coordinator to manage accounts and exam papers and to create new exam papers. 


\section{If $\square$ G.}
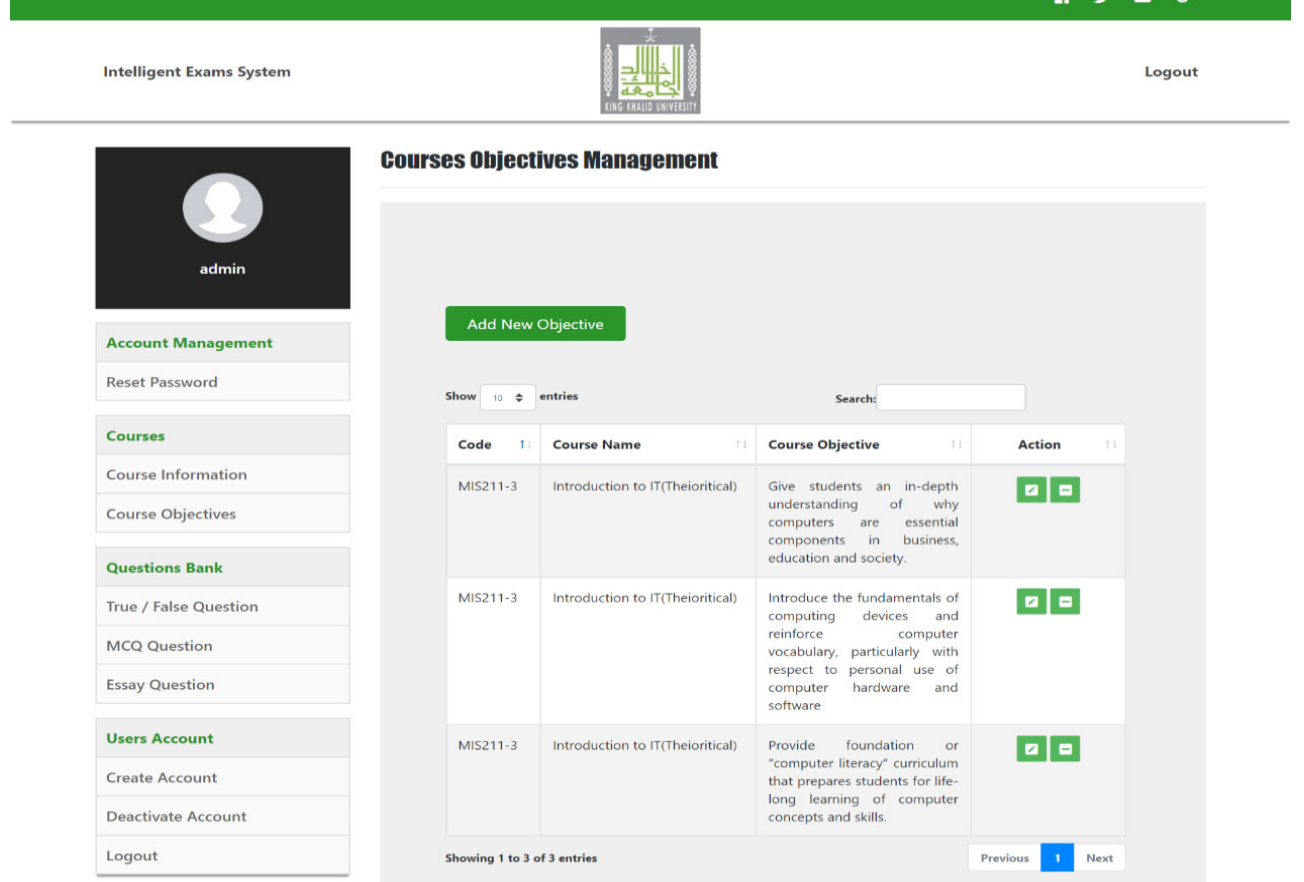

Gourses Objectives Management

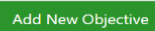

Show $10 *$ entries

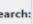

Code th course name

MIS211-3 Introduction to IT(Theioritical)

Action

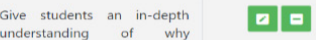

understanding of why

components in business,

education and society.

MIS211-3 Introduction to IT(Theioritical)

Introduce the fundamentals of $\quad\left[\begin{array}{lll}\hline \\ \hline\end{array}\right.$

(n)

reinforce computer

vocabulary, particularly with

computer personal use of

software

MIS211-3 Introduction to IT(Theioritical)

Provide foundation or

"computer literacy" curriculum

long learning of computer

concepts and skills

FIGURE 8. Manage course objectives.

In addition, when questions are updated or modified, this will be reflected in the exam papers produced. The system will allow administrators to print exam papers after automatically generating the exam. This Web-based application tool will help staff in preparing examinations, by creating question papers, reframing the question papers for future use, and providing huge support for administrators in an academic institution. Moreover, it provides an efficient tool to search for particular questions in the repository. The prepared and formatted question papers are provided in very good shape and quality in both soft and hard copies.

\section{Conclusion}

The proposed web-based application is an efficient online tool that assures quality, efficiency, accuracy, and most importantly ease of use. We have developed this system considering every aspect of exams and their preparation. We received feedback from staff that has been used this system and their responses were very encouraging as this system overcomes most of their concerns with accuracy. Furthermore, they suggested extending this study and upgrading the system for all the departments in the institution. We, the 


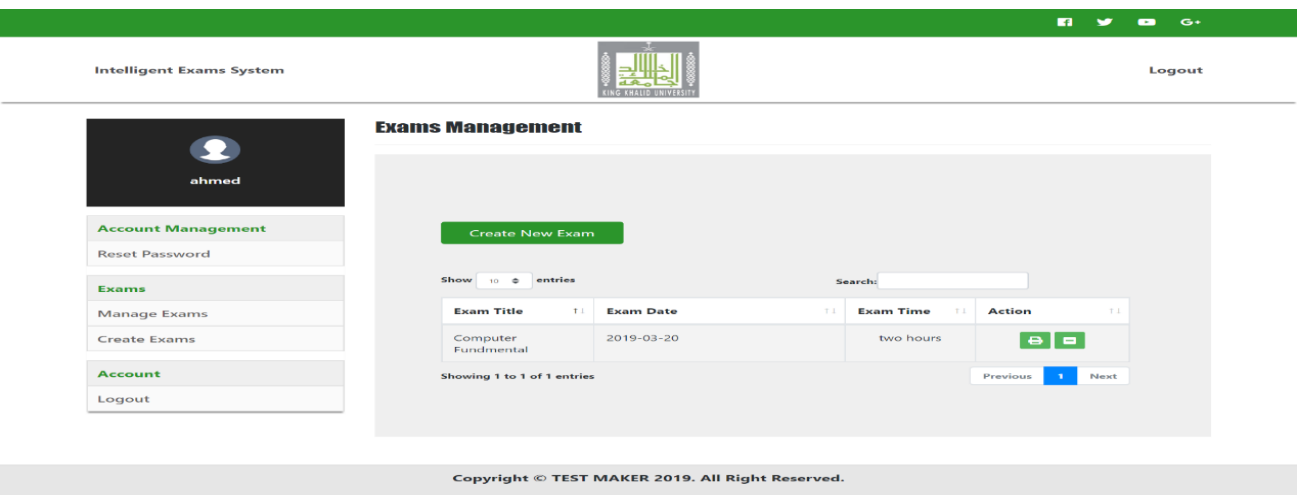

FIGURE 9. Manage exams page.

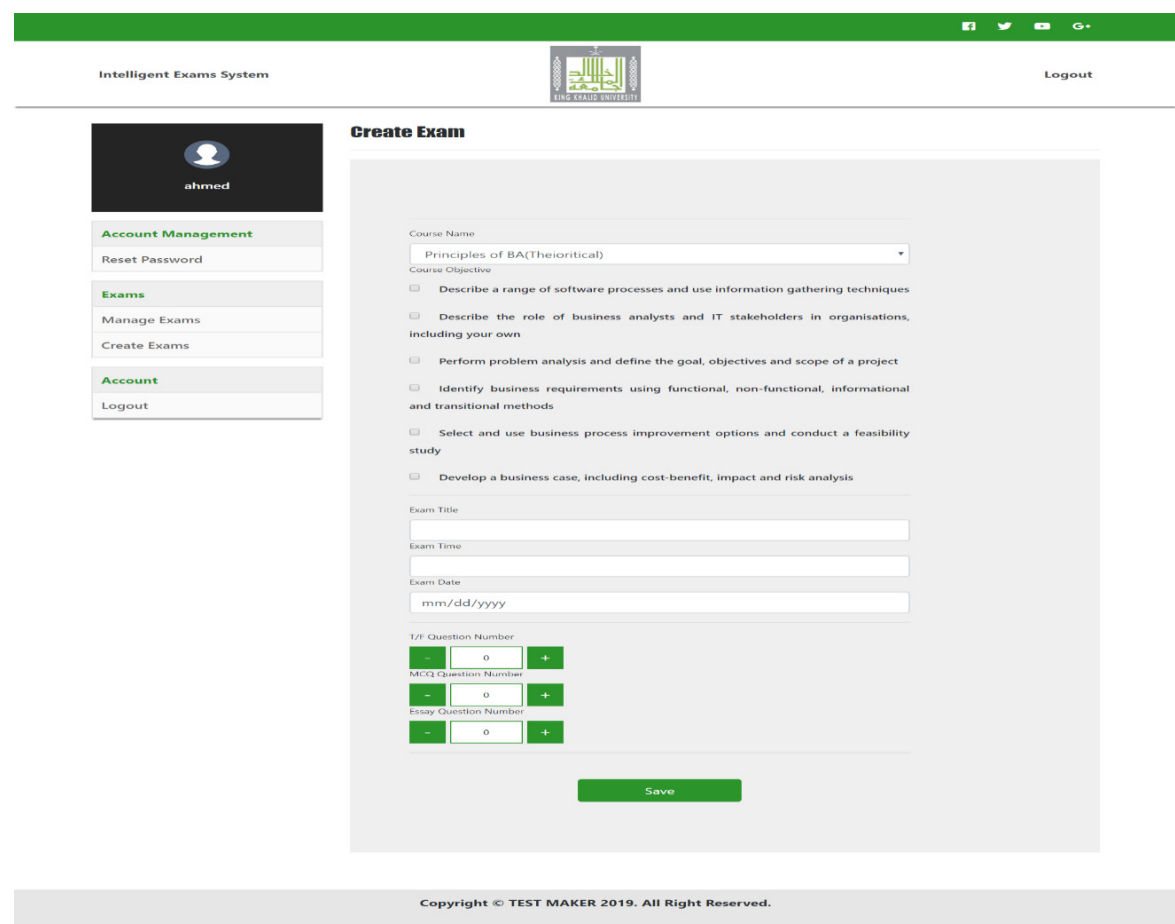

FIGURE 10. Create exam page.

authors, will do everything necessary to widely cover all other courses in the institution and upgrade the system into platform independence.

\section{References}

1. Olson L. Impact of paper-and-pencil. online Testing is Compared Education. 2005, 25(1), 14. https://www.edweek.org/ew/articles/2005/08/31/01online.h25.html

2. Xu Y, Iran-Nejad A, Thoma SJ. Administering defining Issues test online: do response modes matter? Journal of Interactive Online Learning. 2007, 6(1), 10-27. https://www.researchgate.net/ 
publication/255597296_Administering_Defining_Issues_Test_Online_Do_Response_Modes_ Matter

3. Lei Liu, Hui Shi, RuiZhai. The design and implementation of online exam system. Applied Mechanics and Materials. 2014, 678(691), 2506-2509. https://doi.org/10.4028/www.scientific. net/AMM.687-691.2506

4. SakirTasdemir, Mehmet Balc1, AyseCabi, Mustafa Altin, Osman Cabi, The design and application of online exam system supported by database. International Journal of Applied Mathematics, Electronics and Computers. 2015, 3(3), 204-207. DOI: 10.18100/ijamec.43348.

5. Taqi MK, Ali R. Automatic question classification models for computer programming examination: a systematic literature review. Journal of Theoretical and Applied Information Technology. 2016, 93(2), 360-374. http://www.jatit.org/volumes/Vol93No2/14Vol93No2.pdf

6. Qiu-ting JIA. Design of a student's online examination system based on web. In: International conference on education, management and applied social science. 2016. DOI: 10.12783/dtssehs/ emass2016/6761.

7. Atoum Y, Chen L, Liu AX, Hsu SDH, Liu, X. (2017). Automated Online Exam Proctoring. IEEE Transactions on Multimedia. 2017; 19(7), 1609-1624. doi:10.1109/tmm.2017.2656064

8. Li Y. An Application of EDM: design of a new online system for correcting exam paper. Proceedings of the 13th international conference on computer science \& education (ICCSE) conference. 2018. https://doi.org/10.1109/ICCSE.2018.8468821

9. Setyowati MS, Dwirahma A, Hendrawan A. Implementation of Jakarta one online system. Proceedings of the international conference on emerging media, and social science. 2018. http://dx.doi.org/10.4108/eai.7-12-2018.2281788

10. Peter Oluwole Ajewole, John Momoh. Development of a computer-based test platform with a FOSS. International Journal of Engineering and Computer Science. 2014, 3(8), 7811-7817. https://www.researchgate.net/publication/266740337_Development_of_a_Computer-Based_ Test_Platform_with_a_FOSS

11. Hameed MR, Abdullatif FA. Online examination system. International Advanced Research Journal in Science. Engineering and Technology. 2017, 4(3), 106-110. https://doi.org/10.17148/ IARJSET.2017.4321.

12. Garg K, Rastogi K, Pratap Singh R. A review paper on online examination portal. International Journal of Recent Scientific Research. 2019, 10(3), 31822-31824. https://www.recentscientific. com/sites/default/files/13148-A-2019.pdf

13. Systems development life cycle (SDLC). https://en.wikipedia.org/wiki/Systems_development_ life_cycle. Date accessed: 31/12/2019.

14. Dennis WR. Systems analysis \& design. 5th edn. John Wiley \& Sons: United States of America. 2012; 592. https://dl.acm.org/doi/book/10.5555/2544011.

15. Object oriented analysis \& design. O’Reilly Media: United States of America. https://www. tutorialspoint.com/object_oriented_analysis_design/index.htm. Date accessed: 2007.

16. Shelly GB, Rosenblatt HJ. Systems analysis and design. 8th edn. Course Technology: Boston. United States of America. 27. Atlanta, GA, USA, ACM Press. 2010; 115-122. https://epdf.pub/ systems-analysis-and-design-shelly-cashman-series.html. 